Bull. Mater. Sci., Vol. 14, No. 1, February 1991, pp. 65-70. (C) Printed in India.

\title{
Measurement of ultrasonic wave velocity in a solid under gas pressures up to $0.4 \mathrm{GPa}$
}

\author{
C DIVAKAR and A K SINGH \\ Materials Science Division, National Aeronautical Laboratory, Bangalore 560 017, India \\ MS received 3 January 1991
}

\begin{abstract}
A set-up is described for the measurement of longitudinal and transverse wave velocities in a solid under gas pressures up to $0.4 \mathrm{GPa}$. To check the performance of the set-up, the elastic constants of $\mathrm{Se}$ and $\mathrm{As}_{2} \mathrm{Se}_{3}$ glasses and their pressure derivatives were obtained from the wave velocity data and compared with the data available in the literature.
\end{abstract}

Keywords. Ultrasonic wave velocity; gas pressures; elastic constants of glasses.

\section{Introduction}

The elastic constants of an isotropic solid specimen can be accurately determined by measuring the velocities of transverse and longitudinal ultrasonic waves in the specimen. The variation of the wave velocities with pressure can be used to determine the pressure derivatives of the elastic constants (Thurston 1965). This paper describes a set-up for the measurement of ultrasonic wave velocities in solids as a function of gas pressures up to $0.4 \mathrm{GPa}$. The performance of the set-up has been checked by determining the elastic constants and their pressure derivatives of $\mathrm{Se}$ and $\mathrm{As}_{2} \mathrm{Se}_{3}$ glass samples and these have been compared with literature values.

\section{Experimental set-up}

\subsection{High pressure system}

The high pressure system is schematically shown in figure 1. Nitrogen gas at $15 \mathrm{MPa}$ is compressed to high pressure (up to $0.4 \mathrm{GPa}$ ) using a gas booster system (HIP, USA), and led to the pressure bomb which is made out of EN-24 steel and heat-treated to RC 40. The ports for loading the sample assembly and for taking out the electrical leads are sealed using the arrangement described earlier (Cornish and Ruoff 1961; DukYoon 1966). The outer tubing containing a pair of sheathed wires was placed in the central hole of the plug A, and silver-soldered (figure 1b). A small quantity of epoxy was applied to the high pressure end of the sheathed wires, and cured under pressure to prevent the gas leaking through the packing around the wires. The leak between the bomb and the plug is prevented using neoprene $O$ rings. The pressure was measured by a Heise gauge with least count $500 \mathrm{kPa}$, and read to $100 \mathrm{kPa}$ by eye estimation.

\subsection{Specimen preparation}

Selenium and $\mathrm{As}_{2} \mathrm{Se}_{3}$ samples were prepared by the melt quenching method. To 


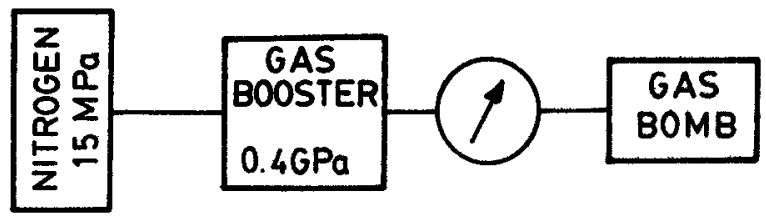

(a)

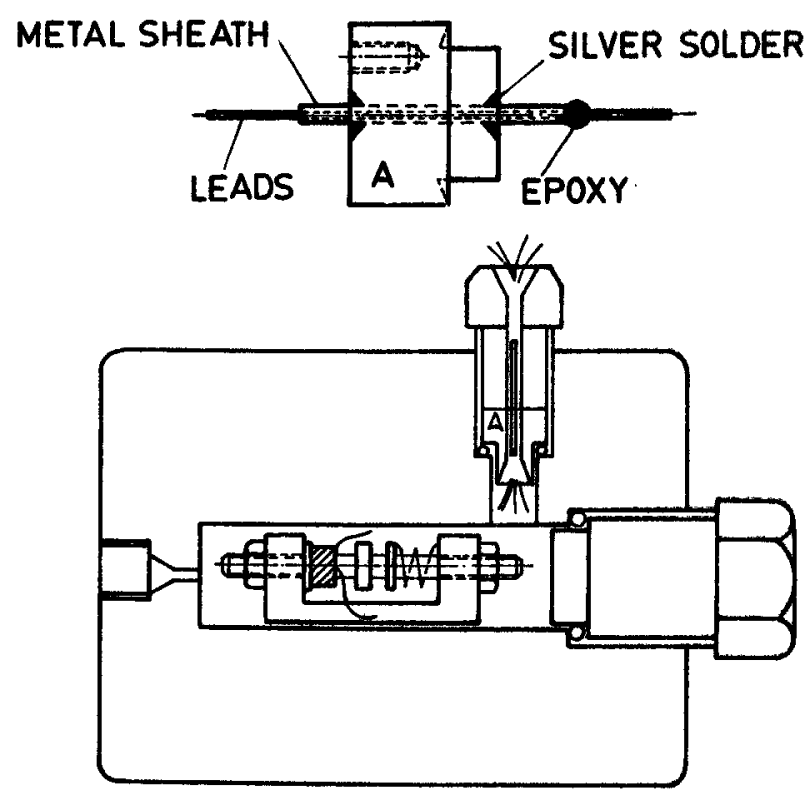

(b)

Figure 1. a. Schematic diagram of the gas pressure system. b. Pressure vessel and sample assembly.

prepare Se samples, a batch of about $12 \mathrm{~g}$ of selenium $(99.999 \%$ pure from Kochlight) was sealed under vacuum in a silica tube (i.d. $12 \mathrm{~mm}$ ) and kept at $350 \mathrm{C}$ for $5 \mathrm{~h}$. The melt was then quenched in air. $\mathrm{As}_{2} \mathrm{Se}_{3}$ samples were prepared by the following procedure. Appropriate amounts of As and $\mathrm{Se}$ (batch of about $12 \mathrm{~g}$ ) were sealed under vacuum in a silica tube (i.d. $12 \mathrm{~mm}$ ). The tube was placed in a rotary furnace and the temperature raised to $600 \mathrm{C}$ at $10 \mathrm{C} / \mathrm{min}$. The tube was continuously rotated while at high temperature. After $5 \mathrm{~h}$, the melt was quenched in cold water. The sample (still in the tube) was then annealed at $180 \mathrm{C}$ for $1 \mathrm{~h}$. The cylindrical samples thus obtained were recovered by dissolving the silica tubes in hydrofluoric acid. The specimens measuring 4 to $10 \mathrm{~mm}$ length were cut with a high speed diamond wheel using coolant. The two flat surfaces were polished and rendered parallel (within $200 \mu \mathrm{rad}$ ). The density of the sample was $4.278 \mathrm{~g} \mathrm{~cm}^{-3}$ for Se and $4.600 \mathrm{~g} \mathrm{~cm}^{-3}$ for $\mathrm{As}_{2} \mathrm{Se}_{3}$. The densities of various samples agreed to within $0.2 \%$. 

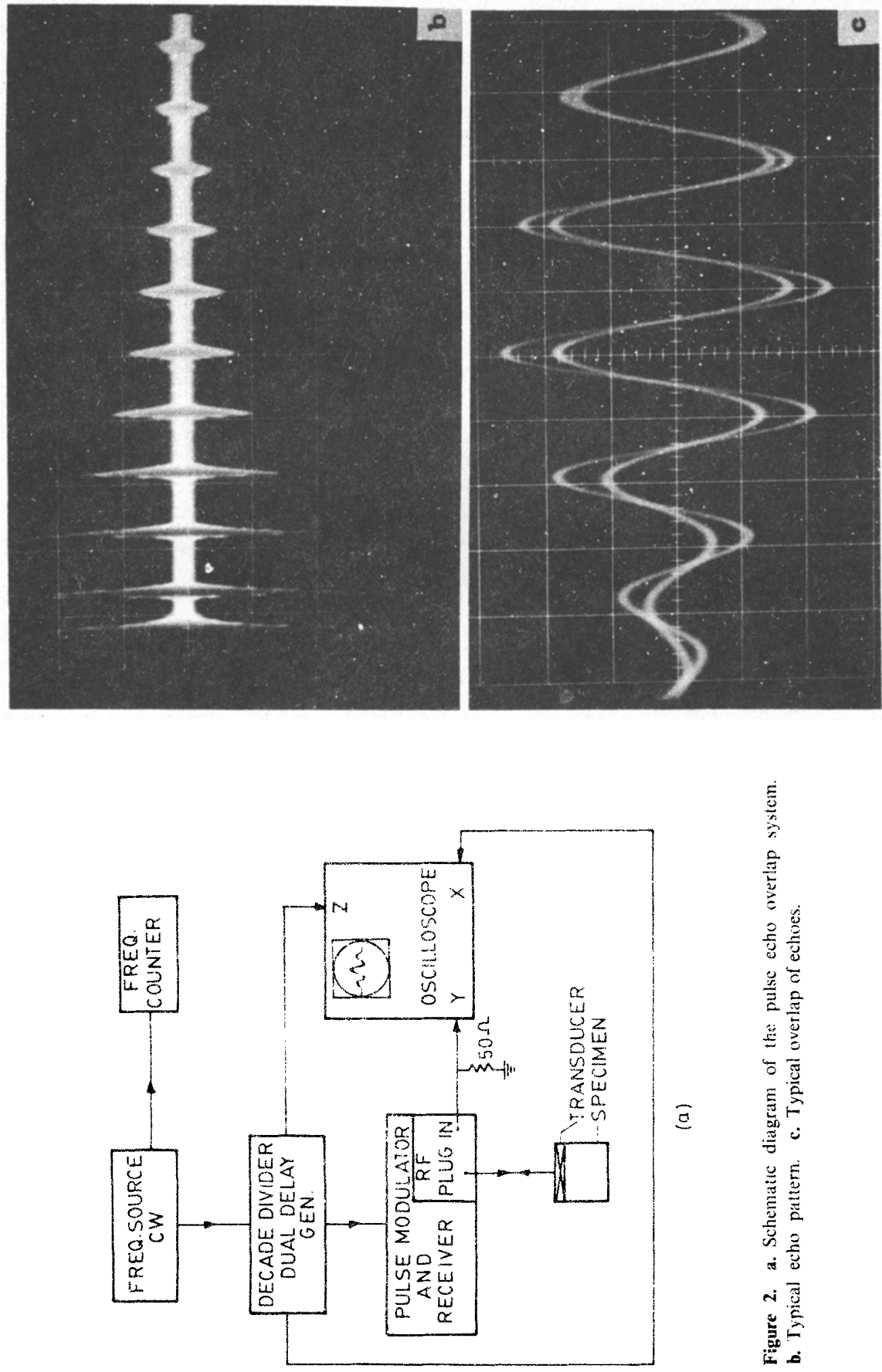


\subsection{Ultrasonic measuring system}

The ultrasonic velocities were measured by the pulso echo overlap method (Papadakis 1964, 1967). The block diagram of the set-up is shown in figure 2(a). $X$ and $Y$ cut quartz transducers with $10 \mathrm{MHz}$ resonant frequency were used for the longitudinal and transverse waves respectively. The transducer was bonded to the sample using salol (phenyl salisilate).

The r.f. pulser (Matec 7700,760 v plug in) was used to excite the transducer fixed onto the sample. The echoes resulting from the back surface of the sample were detected by the same transducer. The received and amplified signals were displayed on an oscilloscope screen (Philips PM 3265). A typical pulse echo pattern is shown in figure 2(b). The $x$ axis of the oscilloscope was triggered at the carrier frequency of the continuous wave (CW) source (Matec model 110) whereas the pulser at a decade fraction of it. When the repetition rate of the $\mathrm{CW}$ source was of the order of inverse of the transit time, an apparent overlap of the echoes was observed on the oscilloscope screen. The observation of the overlap was facilitated by amplifying pulses given to the $z$ axis of the oscilloscope (Matec model 122B). Any two echoes could be selected for transit time measurement. A typical overlap is shown in figure 2c. The McSkimin $\Delta t$ criterion (McSkimin 1961) was used in the determination of the correct cycle-to-cycle overlap between the echoes. The pulse overlap frequency was read on a counter (Aplab model Ic 12). The longitudinal and transverse velocities $\left(v_{l}\right.$ and $\left.v_{l}\right)$ were determined from the pulse overlap frequency $\left(f_{R l}\right.$ and $\left.f_{R t}\right)$ and the length of the sample.

In the pressure experiments, the pressure was increased in steps of $0.01 \mathrm{GPa}$, and after a waiting period of $10 \mathrm{~min}$, the $\mathrm{CW}$ source was adjusted to maintain the overlap. The pressure dependence of the pulse overlap frequencies for both longitudinal and transverse waves was thereby obtained. The ratio $f / f_{0}$ ( $f_{0}$ the frequency at one atmosphere) as a function of pressure up to $0.2 \mathrm{GPa}$ for Se and $\mathrm{As}_{2} \mathrm{Se}_{3}$ glass samples are shown in figures 3 and 4.

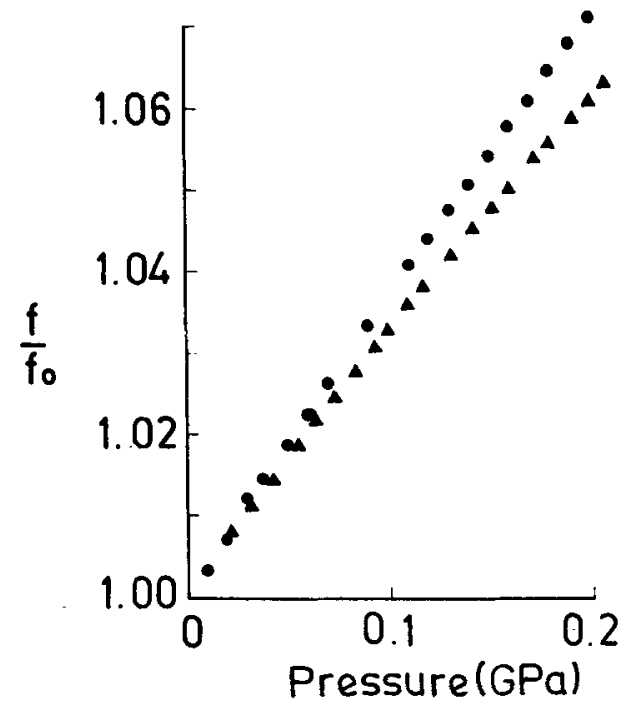

Figure 3. Variation of $f / f_{0}$ with pressure for selenium glass sample. (O longitudinal; $\Delta$ transverse). 


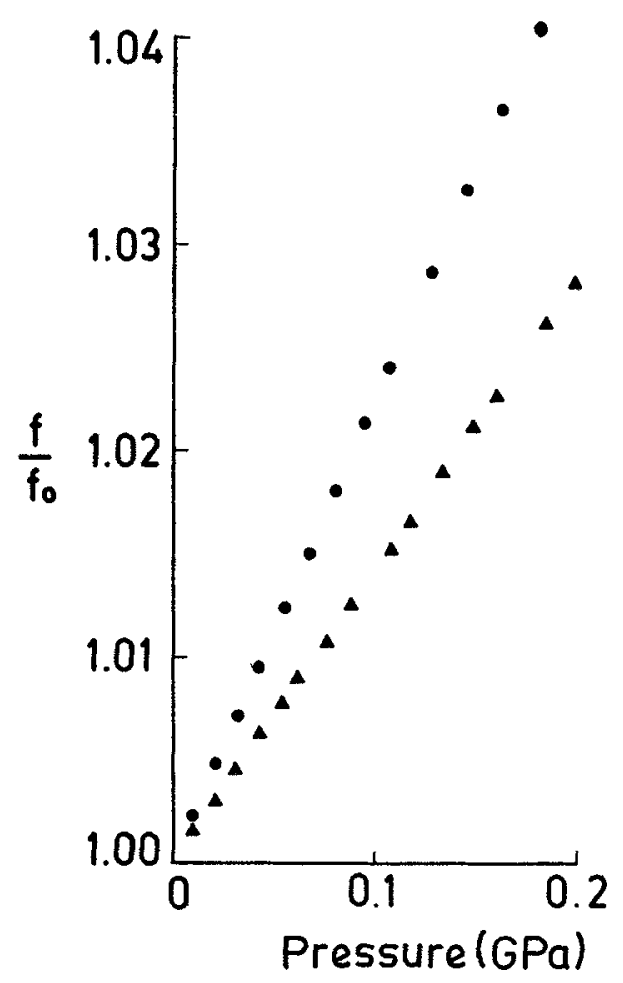

Figure 4. Variation of $f / f_{0}$ with pressure for $\mathrm{As}_{2} \mathrm{Se}_{3}$ glass sample. (O longitudinal; transverse).

The isothermal pressure derivative of the adiabatic moduli were calculated using (Thurston 1965)

$$
\begin{aligned}
& \left(\frac{\partial K_{s}}{\partial P}\right)_{T}=2 L_{s} \frac{\partial\left(f / f_{0}\right)_{l}}{\partial P}-\frac{8}{3} G_{s} \frac{\partial\left(f / f_{0}\right)_{l}}{\partial P}+\frac{1}{3}(1+\alpha \gamma T) \\
& \left(\frac{\partial G_{s}}{\partial P}\right)_{T}=2 G_{s} \frac{\partial\left(f / f_{0}\right)_{t}}{\partial P}+\frac{G_{s}}{3 K_{s}}(1+\alpha \gamma T)
\end{aligned}
$$

where $\gamma$ is the Gruneisen parameter $\left(3 \alpha K_{s} V / C_{p}\right), \alpha$ the linear expansion coefficient, $V$ the atomic volume, $C_{p}$ the specific heat, $L_{s}$ the longitudinal modulus and $G_{s}$ the shear modulus.

\section{Results}

Table 1 shows the values of $v_{l}$ and $v_{t}$ obtained at $298 \mathrm{~K}$ and $1 \mathrm{~atm}$. Also listed are the various adiabatic elastic moduli computed from the velocities and the density using standard formulae. The present results agree well with those reported earlier (Graham and Chang 1965; Vedam et al 1966; Soga et al 1973; Litov and Anderson 1978).

The plot of the pulse overlap frequency $f / f_{0}$ with pressure was linear in the case of 
Table 1. Elastic properties of $\mathrm{Se}$ and $\mathrm{As}_{2} \mathrm{Se}_{3}$ glasses at $298 \mathrm{~K}$.

\begin{tabular}{lcccccc}
\hline & \multicolumn{2}{c}{ Se glass } & \multicolumn{3}{c}{ As $_{2} \mathrm{Se}_{3}$ glass } \\
& $\begin{array}{c}\text { Graham } \\
\text { et al } \\
(1965)\end{array}$ & $\begin{array}{c}\text { Vedam } \\
\text { et al } \\
(1966)\end{array}$ & $\begin{array}{c}\text { Soga } \\
\text { et al } \\
(1973)\end{array}$ & $\begin{array}{c}\text { Present } \\
\text { study }\end{array}$ & $\begin{array}{c}\text { Soga } \\
\text { et al } \\
(1973)\end{array}$ & $\begin{array}{c}\text { Present } \\
\text { study }\end{array}$ \\
\hline$v_{\mathbf{t}} \mathrm{km} \mathrm{sec}^{-1}$ & - & - & 1.826 & 1.827 & 2.261 & $2 \cdot 287$ \\
$v_{\mathbf{t}} \mathrm{km} \mathrm{sec}^{-1}$ & - & - & 0.919 & 0.921 & 1.222 & 1.236 \\
$Y \mathrm{GPa}$ & 9.91 & 9.80 & 9.61 & 9.648 & 17.77 & 17.775 \\
$K_{s} \mathrm{GPa}$ & 9.41 & 9.44 & 9.46 & 9.439 & 14.37 & 14.68 \\
$G_{s} \mathrm{GPa}$ & 3.77 & 3.69 & 3.61 & 3.628 & 6.87 & 7.02 \\
$\sigma$ & 0.324 & 0.327 & 0.331 & 0.330 & 0.294 & 0.294 \\
\hline
\end{tabular}

Table 2. Pressure derivatives of the elastic properties of $\mathrm{Se}$ and $\mathrm{As}_{2} \mathrm{Se}_{3}$ glasses at $298 \mathrm{~K}$.

\begin{tabular}{|c|c|c|c|c|}
\hline & \multicolumn{2}{|c|}{ Se glass } & \multicolumn{2}{|c|}{$\mathrm{As}_{2} \mathrm{Se}_{3}$ glass } \\
\hline & $\begin{array}{l}\text { Soga et al } \\
\text { (1973) }\end{array}$ & Present study & $\begin{array}{c}\text { Soga et al } \\
\text { (1973) }\end{array}$ & Present study \\
\hline$\left.\left[\partial\left(f_{R} / f_{R 0}\right) / \partial P\right)\right]_{T} \mathbf{G P a}^{-1}$ & $4.03 \times 10^{-1}$ & $4.18 \times 10^{-1}$ & $2.20 \times 10^{-1}$ & $2.24 \times 10^{-1}$ \\
\hline$\left.\left[\partial\left(f_{R} / f_{R 0}\right)_{t} / \partial P\right)\right]_{T} G^{-1}$ & $3.50 \times 10^{-1}$ & $3.53 \times 10^{-1}$ & $1.43 \times 10^{-1}$ & $1.41 \times 10^{-1}$ \\
\hline$\left(\partial K_{s} / \partial P\right)_{T}$ & $8 \cdot 5$ & 8.52 & $8 \cdot 1$ & 8.046 \\
\hline$\left(\partial G_{s} / \partial P\right)_{T}$ & $2 \cdot 7$ & $2 \cdot 694$ & $2 \cdot 141$ & $2 \cdot 126$ \\
\hline
\end{tabular}

$\mathrm{As}_{2} \mathrm{Se}_{3}$ glass and a least square fit was made to obtain the derivative with respect to pressure. The $f / f_{0}$ versus $p$ data was nonlinear in the case of selenium sample. A parabolic fit was made and the coefficient of the $p$ term is given in table 2. The pressure derivatives of the elastic moduli calculated using (1) and (2) are also shown in table 2. The agreement between the present values and those reported earlier (Soga et al 1973) is good.

\section{Acknowledgement}

The authors sincerely thank Mr A Giridhar and Mr P M Jaman for assistance in the preparation of the glass samples.

\section{References}

Cornish R H and Ruoff A L 1961 Rev. Sci. Instrum. 32639

DukYoon 1966 Rev. Sci. Instrum. 371611

Graham L J and Chang R 1965 J. Appl. Phys. 362983

Litov E and Anderson O L 1978 Phys. Rev. B18 5705

McSkimin H J 1961 J. Acoust. Soc. Am. 3312

Papadakis E P 1964 J. Appl. Phys. 351474

Papadakis E P 1967 J. Appl. Phys. 421045

Soga N, Kunugi M and Ota R 1973 J. Phys. Chem. Solids 342143

Thurston R N 1965 IEEE Proc. 531320

Vedam K, Miller D L and Roy R 1966 J. Appl. Phys. 373432 